\title{
Incorporating service-learning in the Spanish classroom: Challenges and solutions
}

\author{
Emilia Alonso Marks \\ Department of Modern Languages \\ Institute for the Empirical Study of Language \\ Ohio University
}

Received: 28 April 2007 / Accepted: 13 September 2007

ISSN: $1697-7467$

\begin{abstract}
The present paper assesses the effect of incorporating a service-learning component into a Spanish Education class. Twenty Ohio University students participated in the study. The students organized a one-day Spanish pronunciation workshop with a group of High School students from an underserved, rural area. In general, the college students evaluated the experience very positively. Their main satisfaction derived from being able to apply their knowledge while reaching out to the community. However, they also reported difficulties adapting their teaching materials and organizing themselves efficiently. They felt the role of their instructor was decisive in the success of their project.
\end{abstract}

Key words: service-learning, foreign language teaching, Spanish as a foreign language, community service.

RESUMEN: Este trabajo evalúa el efecto de incorporar un componente de aprendizaje basado en actividades de servicio a la comunidad en la clase de español como lengua extranjera. Veinte estudiantes de la Universidad de Ohio participaron en el estudio. Organizaron un taller de pronunciación con un grupo de estudiantes de secundaria de una zona rural desfavorecida. En general, los universitarios evaluaron la experiencia positivamente. Su principal satisfacción radicaba en poder aplicar los conocimientos mientras se aporta un servicio a la comunidad. Pero también tuvieron dificultad para adaptar sus materiales docentes y organizarse eficazmente. Consideraban el papel del profesor decisivo para el éxito de su proyecto.

Palabras claves: aprendizaje basado en el servicio, enseñanza de la lengua extranjera, el español como lengua extranjera, servicio a la comunidad.

\section{INTRODUCTION}

In his 1997 opus, Edward Zlotkowski describes service-learning (SL) as a method under which students learn and develop through thoughtfully-organized service. The service component of the learning experience needs to meet the following criteria: (a) Is conducted in and meets the needs of a community and is coordinated with an institution of higher education, and with 
the community; (b) helps foster civic responsibility; (c) is integrated into and enhances the academic curriculum of the students enrolled; and (d) includes structured time for students to reflect on the service experience.

The value of integrating SL in higher education does not only lie in the opportunities it affords students to confirm their mastery of academic subjects. SL projects are meant to supplement, complement, and qualify the contents students have learned through traditional lecture and discussion methods in the classroom. As Zlotkowski (2001:28) indicates, these activities need to engage students in projects that address an unmet necessity of the community and to include "reflective activities that seek to turn simple exposure into a deliberately constructed learning opportunity". Similarly, Weigert (1998) stressed the importance of reflection on the community service provided for the SL experience to have meaningful learning value. Therefore, while in the community students provide some meaningful service that meets a need or goal, on campus students provide a service that "flows from and into course objectives, is integrated into the course by means of assignments that require some form of reflection on the service in light of course objectives, and the assignment is assessed and evaluated accordingly" (Weigert, 1998:3-10). In this sense, incorporating SL activities into a regular, formal, higher education course would pair traditional assignments, such as papers, class presentations and exams with other assignments that are of a more proficiency-oriented nature. For example, they might assess the needs of a company and design a product of technological value; teach concepts or a particular skill to an underserved or underrepresented group of learners, such as, tutoring Spanish-speaking school-age students, offering English as a Second Language (ESL) classes to Latin-American restaurant workers; or serve as interpreters or translators for a town police department or for court, connecting that way with local Latino cultures and communities on campus and/or outside of campus.

When applied to Spanish, one of the positive aspects of SL is that the students who serve are able, more readily, to identify themselves as learners because, from the outset, the experience affords them the opportunity to practice their language skills in authentic situations. It has long been accepted in the literature that foreign language (FL) education also contributes tremendously to multicultural learning and understanding. Nevertheless, it has only been within the last five or six years that the connection between FL learning and SL has been recognized widely and in an explicit manner. In 1999, Hellebrandt and Varona published a seminal work entitled Construyendo Puentes (Building Bridges): Concepts and Models for Service-Learning in Spanish. The book is a collection of twelve essays written by different college instructors who have been experimenting with and exploring the connection between Spanish and SL. It is organized in three sections, namely, SL as theory, SL from the classroom, and SL in local and international communities. In her Foreword to Construyendo Puentes, Tesser (AATSP President at the time) cites the Standards for Foreign Language Learning: Preparing Students for the $21^{\text {st }}$ Century to link clearly the goals of FL learning with those of SL: "the ultimate goal of language teaching and learning, as reflected in the Standards document, is to provide the learner with the ability to continue developing language and cultural knowledge through lifelong experiences within the context of, in this case, Spanish-speaking communities" (p. ix). Indeed, cultural understanding (whether interpreted as culture with a capital C, plain culture or counter-culture, to use Miquel and Sans' 1996 categorization) has always been a major goal in the teaching of Spanish. In a college setting, the ability of students to connect with the Latino community on campus and/or outside of campus, in a dramatic increase 
across the US, also assists in meeting institutional goals related to exposure to diversity, multicultural learning and understanding. In addition, to help students develop multicultural competence, most international studies programs and FL departments are requiring that majors and minors spend at least a quarter or a semester abroad.

In their efforts to reconnect higher education with communities beyond the campus, educators and education administrators have noticed how important a role faculty could play in incorporating SL activities across academic disciplines. To that end, faculty's role would need to be redefined. As explained before, the traditional lecture-discussion format, while useful for some purposes, has to be challenged in order to accommodate more collaborative learning efforts such as problem-solving activities, activities that promote thinking critically and creatively, projects that require communicating effectively, or community-based projects. For the successful implementation of such projects, the role of faculty is not just crucial in curricular design; faculty faces other challenges. Some of these challenges are relating to students as co-participants in expertise, being flexible with the time students spend in the classroom versus working on their own, and keeping in mind the social, real life dimension of the SL project when it comes to the reflection phase (otherwise it becomes a regular project evaluation where content mastery is key). In the case of Spanish education, there are other aspects colleges may take into consideration, namely, encouraging instructors to interact with and serve their local Spanish-speaking community and even to spend time abroad in order to have a more profound understanding, of both local and international socio-political issues. These experiences will undoubtedly help instructors articulate communication, diversity, multicultural understanding and involvement as specific goals for a variety of SL placements within their local community.

The purpose of the present paper is to assess the planning, monitoring and implementation of a SL project as it tied pedagogically with the academic content and objectives of a Spanish Education class. This assessment is done in light of the definitions of SL provided by leading authorities in the field such as Zlotkowski (1997), Weigert (1998), and Hellebrandt and Varona (1999). In examining the college students' participation in their SL project, the study took into consideration two variables, namely, the learning value of the SL experience (e.g. practicing skills in an authentic situation, providing meaningful service that meets a need in the community, developing language and cultural knowledge); and the role of the instructor as facilitator of the SL experience (e.g. articulation of communication, cultural understanding and community involvement as course objectives, ability to relate to students as co-participants, flexibility to accommodate the demands of implementing the SL project). Thus, although a few percentages are included in the results section, the study is mostly qualitative in nature.

\section{Method}

\subsection{Participants}

Twenty Ohio University students (9 graduate and 11 undergraduate) participated in the study. During an academic quarter, they were all enrolled in a Spanish Applied Phonetics course that included a SL component. 
The instructor was a bilingual Spanish-English speaker and a FL instructor with eighteen years of teaching experience. She had attended a six-week SL seminar at Ohio University, and an Ohio Campus Compact conference to learn about the discipline. As an active member in her local community, she had an in-depth understanding of its needs. She followed Ohio University criteria for designation of service-learning courses (What is Service-Learning, 2005). Her students, on the other hand, had not had any previous SL experience. All of these students were pursuing either a Spanish major or a Spanish Education major. Most had indicated that their career goal was to become high school (HS) teachers.

\subsection{The Service-Learning Component}

For their SL project, students identified a local HS in an economically disadvantaged rural community. As a class, they contacted the Spanish teacher to explore the viability of creating a joint SL project with her students. The parties agreed to organize a one-day Spanish pronunciation workshop for a group of interested HS juniors and seniors who were studying Spanish. The workshop was also going to serve the purpose of introducing these HS students to the college campus and to college life. The SL component required that each college student be assigned to two different types of teams, one type (content teams) dealing with the academic focus (Spanish phonetics, in this case) and the other (task teams) directing those tasks that needed to be performed for the successful completion of the entire project.

Students designed and distributed themselves into five content teams:

1. Tongue twister, name-sound guessing team: This team created oral production, didactic activities and games for the HS students.

2. Song team: Students in this team practiced oral production activities using songs in Spanish.

3. Poem-recitation team: This team selected poems in Spanish and had the HS students both read them aloud and analyze any pronunciation difficulties they encountered.

4. Drama performance team: This team put together a play that included jargon in present-day Spanish for the HS students to perform.

5. Dialectology team: Students in this team selected several passages using different Spanish dialects, such as Castilian Spanish, Caribbean Spanish, Argentinean Spanish, etc. They had the HS students read them aloud, analyze and compare the most salient features in each dialect against the standard Spanish variety.

There were two task teams. These teams worked on all of the additional non-content related tasks for the successful implementation of the workshop:

1. On-campus visit team: Students in this team were responsible for scheduling a visit to different college facilities, including the Language Resource Center, the Main Library, the Gym, and one of the Residence Halls. In addition, this team was in charge of making reservations at a local restaurant for lunch, and preparing the final agenda for the workshop.

2. Public relations team: This team was responsible for handling name tags for participants, for checking with the University's health department on any required permits and policies for serving or storing soft drinks, and for gaining coverage of the event by the local media. 
Although all four parties, namely, the college students, their professor, the HS students, and their teacher were responsible for evaluating the experience, for the purpose of the present paper I will focus on the data obtained from the college students' evaluations and their professor's final assessment of the SL project. Students had to submit two evaluations. In the first, they commented on the academic workshop (for example, the difficulties they may have experienced while preparing their part of the workshop, the aspects that they enjoyed most and least) as well as on their involvement in the different teams (for example, how many times they met during the quarter, whether or not everyone participated equally). In the second, they assessed the overall value of the SL assignment by means of narrative reflections. (For a sample of the complete evaluation form, please see Appendix A).

\section{RESUlts}

Overall, the college students' evaluation forms indicated that they did not encounter any special difficulties that marred their experience and therefore valued it as a pleasant, successful learning opportunity. To question 1 - What difficulties did you come across while preparing your part of the workshop? - 90\% of the responses revolved around the idea that adapting the content material to the HS students' level was especially cumbersome. Other responses mentioned difficulties related to the logistics of finding a good time to meet.

Students felt that their group members participated equally or for the most part equally. Although, in general, students reported having no problems meeting with their groups, $15 \%$ of them mentioned experiencing a few problems, including getting their schedules to coincide.

In terms of the aspects of the workshop students liked the most, $90 \%$ of the responses emphasized the idea of sharing, collaborating, and reaching out to the community. The rest of the students (10\%) stressed their own enjoyment in participating in the workshop. The aspects that students disliked the most were those involving the logistics of organizing such workshop (100\% of the students addressed this issue). For example, the idea that the HS students could have used more hands on activities, scheduling it at the end of the quarter when students are getting ready for finals, or coping with unexpected time constraints or organizational problems for their presentations. All of them felt that having more direction from their instructor would have been decisive in the success of their project. Still, the positive aspects far outweighed the negative ones in number. On average students provided five positive comments versus two negative ones.

With regards to the value of this assignment, most of the students' reflective narratives indicated that it was both a good learning experience and a good field work experience. Other students put the emphasis on the benefits derived from group effort and collaboration with peers, while still others focused on the value of the experience for the HS students.

As reflected on her assessment of the SL experience, the instructor succeeded in articulating communication, cultural understanding and community involvement as course objectives. Her students communicated and were able not only to transmit their knowledge of Spanish phonetics but also to apply it to a real life situation, by helping HS Spanish students hone their pronunciation skills. The activities her students created exposed HS students to Latino culture through poems by Nicolás Guillén that portrayed Spanish speakers difficulties with English, songs 
that aim at promoting cultural understanding, or presentations that depicted the influence of indigenous people, such as the Nahuatl, on Mexican Spanish vocabulary. The instructor took in her students as co-participants in expertise, as language instructors themselves, and provided them with opportunities outside of class to work on their project. Overall she reported that developing the SL project was a very rewarding experience because it enhanced her students' learning of the subject matter, namely, Spanish pronunciation concepts, they learned how to apply these concepts in a real life context, and how to serve their local community by providing an unmet need.

\section{Discussion}

The college students evaluated the experience very positively. Their main satisfaction derived from being able to apply their knowledge while reaching out to the community, practicing Spanish in a real-life context and providing a meaningful, rewarding service to an underserved community of learners. A recurrent comment was: "It was a good opportunity to use what we learned in class in a different setting. If you want to learn it well, learn to teach it!" (Lydia). However, students also reported experiencing difficulties adapting their teaching materials to the HS students' level and problems in successfully and efficiently organizing themselves so that each team member had clear goals in mind. In addition, students felt that they needed more direction since they were not used to providing any type of community service prior to this project.

With regards to the value of this assignment, most of the students' reflective narratives indicated that it was both a good learning experience and a good field work experience. Other students put the emphasis on the benefits derived from group effort and collaboration with peers, while still others focused on the value of the experience for the HS students. Overall students perceived the SL project as mutually beneficial for all the parties involved. They were able to work collaboratively toward a common goal, namely, to practice their Spanish skills in an authentic context through engaging and meaningful interactions with Spanish learners. On the one hand, the college students "used what [they] learned in class in a true communicative setting, and [the experience] let them know that they could communicate their enthusiasm and love of Spanish to others" (Gerry). On the other, the HS students realized that "learning can be fun and when learning is made fun one usually gets more out of it. It can be really fun to speak español all day!" (Maryann). Both, the college students and the HS students, felt that there was a true mutual exchange sparking their motivation and enthusiasm to communicate in Spanish. By reflecting on their work in the community, the college students were able to discover valuable lessons, both academic and personal. The SL project taught them how to apply knowledge of an academic subject matter in a meaningful context. The experience afforded them opportunities for self-discovery, self-reflection, and self-worth as community members and as teachers. The SL project definitely enhanced their sense of civic engagement by making them aware of a socio-economic problem that needed involvement from the community in order to be minimized. In their own words: "The project served as a great field experience. We learned about ourselves, about those we are working with, and about those we are providing a service for. It proved to be a wonderful interaction piece, since it gave real results and interactions above and beyond a normal classroom setting" (Jim). 
The role of the instructor was crucial in the planning and implementation of the SL project. Her assets included successful articulation of communication, cultural understanding, and community involvement as course objectives; working with her students in shared expertise; and affording them with opportunities outside of class to develop their ideas and reflect on the SL experience. However, as indicated above, students reported several difficulties which included adapting their teaching materials to the HS students' level, problems in efficiently organizing themselves in teams and in articulating clear goals. Since students had not had any previous SL experience, they felt that they needed more specific directions from their instructor. In light of the preliminary results of the present study, before implementing a SL project, it might be useful for SL instructors to keep the following considerations in mind:

1. Prior to developing their own SL project, students could benefit from reading about or being exposed (e.g. by bringing in a speaker or an SL educator) to similar SL projects that have been successful.

2. Students could also benefit from receiving very specific instructions on what is expected from them and what they need to do.

3. Students need ample opportunities to develop and implement plans and activities for their project and instructors devote more class time to developing strategies for the completion of the workshop (for example, ask students to give mock presentations in front of the class so that they can get feedback from their peers).

4. Students could benefit from giving periodic reports on what they are doing in their teams and to keep a log for purposes of evaluation and accountability.

\section{Conclusion}

The benefits of SL are unquestionable. For students, SL is an opportunity to apply the concepts they have learned in the classroom; to explore careers, develop occupational skills and establish professional connections; to improve their sense of citizenship, social responsibility and commitment to their community; and also to enhance their personal growth. SL also fosters students' motivation because it renders topics relevant to them by engaging and involving them in an issue of real social value they need to address. The SL project taught students how to apply knowledge of an academic subject in an authentic, meaningful context. The SL experience proved to be mutually beneficial for both communities of learners.

The role of faculty is also decisive in the successful incorporation and implementation of SL activities. Instructors need to articulate clear goals and create opportunities for collaborative thinking and shared expertise. Students need guidance and supervision and, at the same time, flexibility in terms of the time afforded to them for planning and creating activities related to their projects both during class and outside of class.

One of the purposes of integrating a SL component in the Spanish Applied Phonetics class described in this study was to allow students of Spanish the opportunity to use their language skills outside the classroom and to present information about the Spanish language and culture to HS Spanish students from an underserved, rural community. In doing so, the students became engaged in a successful learning experience involving higher-level thinking skills, and at the same time, fulfilled an unmet community need. 
The benefits reported in this study can be understood as ways to work beyond different challenges: academic, communicative, cultural, socio-economic, and personal, to name the most salient ones. The success of implementing a SL project requires careful planning and preparation, but it ultimately seems to lie on our desire and determination to tear down the walls that retain us, faculty and students, within the comforts of the academic world and prevent us from reaching out to the community, sharing our expertise, communicating at a deeper level, making a difference, and growing as individuals in an ever-changing global environment.

\section{REFERENCES}

Hellebrandt, J. \& Varona, L.T. (eds.)(1999). Construyendo Puentes (Building Bridges): Concepts and models for Service-Learning in Spanish. Washington, DC: AAHE.

National Standards in Foreign Language Education Project. (1999). Standards for Foreign Language Learning in the $21^{\text {st }}$ century. Yonkers, NY: ACTFL.

Miquel, L. \& Sans, N. (1996). El componente cultural: Un ingrediente más de las clases de lengua. Cable Dossier, 15-21.

Weigert, K.M. (1998). “Academic service learning: Its meaning and relevance," in E. Zlotkowski, Academic Service Learning. San Francisco, CA: Jossey-Bass, 3-10.

What is Service Learning? (2005). Retrieved March 25, 2005, from Ohio University's Community Service Homepage, http://www.ohiou.edu/commserv/servlern/servlern.htm

Zlotkowski, E. (1997). Writing the community: Concepts and models for Service-Learning in Composition. Service-Learning in the Disciplines. Washington, DC: AAHE.

Zlotkowski, E. (1998). Academic Service Learning. San Francisco, CA: Jossey-Bass.

Zlotkowski, E. (2001). "Mapping new terrain: Service-learning across the disciplines". Change, January-February, 25-33. 


\section{APPENDIX A}

The Spanish Sounds Workshop

Spanish 4/537: Applied Phonetics

Department of Modern Languages

Ohio University

\section{Evaluation I: Your involvement}

- What difficulties did you come across while preparing your part of the workshop?

- Did everyone in your group participate equally?

- Did you have any problems meeting with your group?

- How many times did your group meet throughout the quarter?

- What did you think of the workshop? Which aspects of it did you like? Which ones did you dislike? Why?

\section{Evaluation II: The value of the assignment}

- What value did this assignment have for you? Explain 